Military Technical College

Kobry El-Kobbah, Cairo, Egypt.

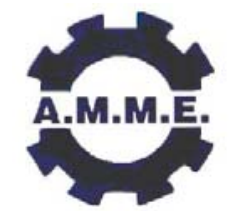

$13^{\text {th }}$ International Conference on Applied Mechanics and Mechanical Engineering.

\title{
A COMPARISON BETWEEN FLOWS OF THREE REACTION SYSTEMS THROUGH SUPERSONIC PROPULSIVE NOZZLES
}

\author{
KEMRY*M.M. and EL-KADY ** E.A.A.
}

\begin{abstract}
The present study is concerned with the analytical solution of frozen flows of combustion gases through the supersonic region of an axisymmetric nozzle. The product gases of $\mathrm{C}_{12} \mathrm{H}_{26}-\mathrm{O}_{2}, \mathrm{H}_{2}-\mathrm{O}_{2}$ and $\mathrm{H}_{2}-\mathrm{F}_{2}$ reaction systems are considered. $A$ predictor-corrector method is employed for approximating the differential terms of the governing equations; while the method of characteristics is used to solve the resulting equations for variable specific heat ratio. The study includes a comparison of the results of the three reaction systems. The results involve the flow field parameters; namely , the temperature $\mathrm{T}$, the pressure $\mathrm{P}$, the velocity $\mathrm{V}$ and Mach number $\mathrm{M}$. The results of the propulsion Parameters namely; thrust force $F$, the specific impulse $I_{s p}$, specific impulse based on fuel combustion $I_{s p, f}$ and thrust efficiency $\eta_{f}$ are also presented. All results are presented for a combustion chamber dimensionless pressure, $P_{c}=30$, an equivalence ratio, $\Phi=1$, a dimensionless throat radius of curvature of the nozzle, $\rho_{t}=2$, and a straight nozzle wall angle, $\psi=20^{\circ}$, as a controlling factors. Results show that the point of tangency at nozzle wall is a source of creating oblique shock waves. The $\mathrm{C}_{12} \mathrm{H}_{26}-\mathrm{O}_{2}, \mathrm{H}_{2}-\mathrm{O}_{2}$ reaction systems produce approximately equal thrusts which are higher than that produced by $\mathrm{H}_{2}-\mathrm{F}_{2}$ reaction system. Besides, the specific impulse attained by $\mathrm{H}_{2}-\mathrm{F}_{2}$ system is of highest magnitude; and there are negligible influences of the three systems on the thrust efficiency.
\end{abstract}

\section{KEY WORDS}

Frozen flow of combustion gases - Characteristic lines - Method of characteristics Initial and boundary value problems - Supersonic flow - Thrust force - Specific impulse - Thrust efficiency.

* Prof., Mechanical Engineering Department, Al-Azhar University, Cairo, Egypt.

** Associate Prof. , Mechanical Engineering Department, Al-Azhar University, Cairo, Egypt. 


\section{NOMENCLATURE}

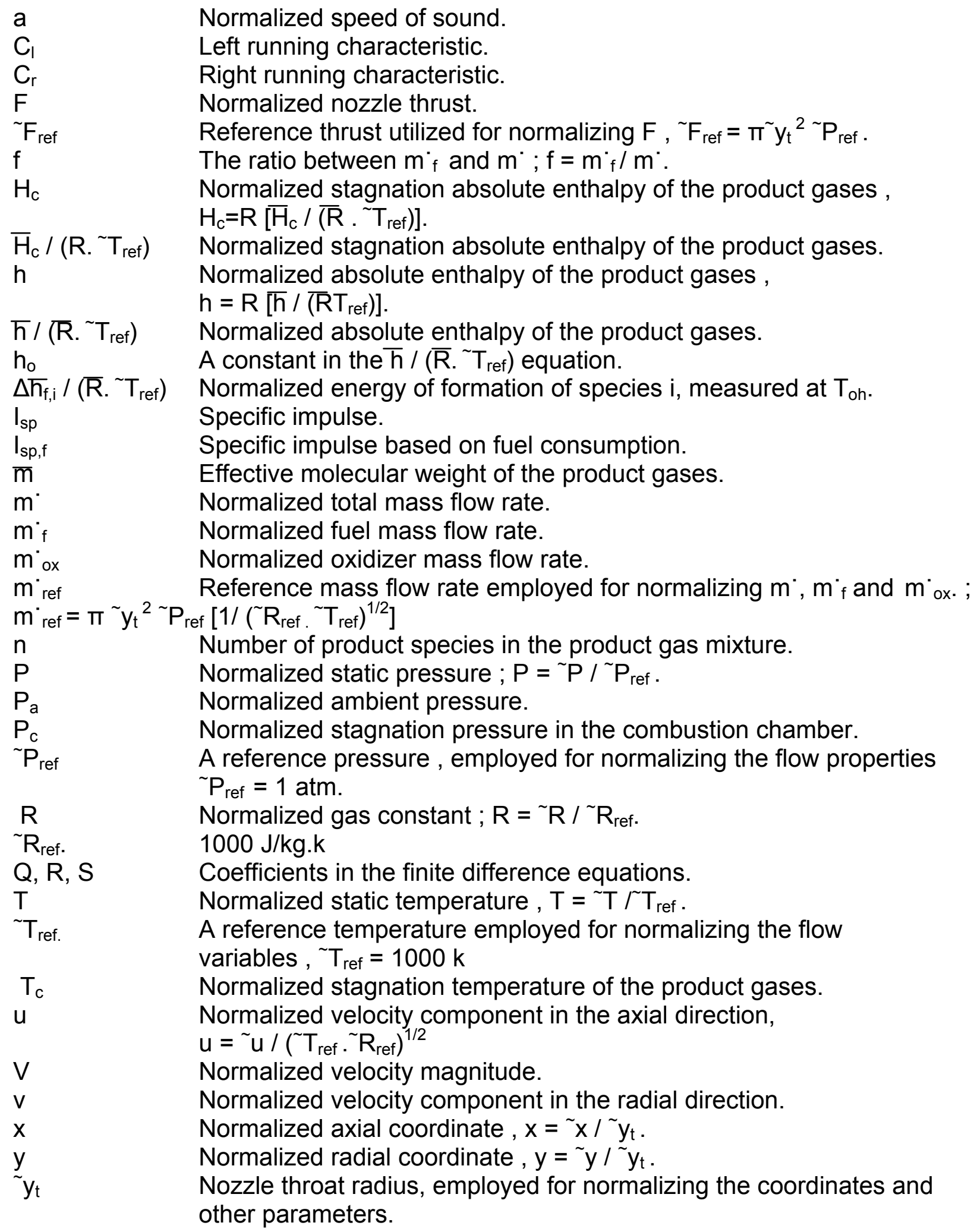

\section{Greek letters}

$\begin{array}{ll}\alpha & \text { Mach angle, } \alpha=\sin ^{-1}(1 / \mathrm{M}) \\ Y & \text { Specific heat ratio. } \\ \varepsilon & \text { Turning angle along the circular arc. }\end{array}$


$\Psi$

$\eta_{\mathrm{F}}$

$\theta$

$\lambda_{l}$

$\lambda_{r}$

$\rho$

$\rho_{\mathrm{t}}$

$\Phi$

$\varphi$

\section{Subscripts}

\section{C}

$\mathrm{Cl}$

I,II,III

f

I

od

ox

$r$

S

W
Angle of the straight nozzle wall.

Thrust efficiency, $\eta_{F}=F / F_{\text {od }}$.

Flow (streamline) angle , $\theta=\tan ^{-1}(\mathrm{v} / \mathrm{u})$.

Slope of $C_{l}$-characteristic, $\lambda_{l}=\tan (\theta+\alpha)$

Slope of $C_{r}$-characteristic, $\lambda_{r}=\tan (\theta-\alpha)$

Normalized density.

Normalized throat radius of curvature, $\rho_{t}=\tilde{\sim} \rho_{t} / \bar{y}_{t}$.

Equivalence ratio

(actual fuel to oxidizer ratio/stoichiometric fuel to oxidizer ratio).

$$
\int_{T o s}^{T} \frac{\overline{\mathrm{C}}_{\mathrm{p}, \mathrm{i}} \mathrm{dT}}{\overline{\mathrm{R}} \mathrm{T}}
$$

\section{Superscripts}

Stagnation properties in combustion chamber.

Centerline.

Flow properties as predicted by $\mathrm{C}_{12} \mathrm{H}_{26}-\mathrm{O}_{2}, \mathrm{H}_{2}-\mathrm{O}_{2}$, and $\mathrm{H}_{2}-\mathrm{F}_{2}$ systems respectively.

Fuel.

Left-running characteristic.

One-dimensional quantities.

Oxidizer.

Right-running characteristic.

Solution point.

Wall.

\section{Superscripts}

Properties based on mole basis.

Properties based on dimensional basis (SI units).

\section{INTRODUCTION}

The importance of investigating the behavior of flow under several conditions in supersonic propulsive nozzles comes from the fact that they are widely used in practical applications. Examples are the nozzles of rocket motors and these of breathing jet engines. The problem of flow of combustion gases through these types of nozzles involves so many parameters which influence the flow behavior. Among these parameters, the nozzle geometry, the reaction modeling, dimensions of flow on which solution is based upon as well as the method of solution are some examples. The flow through nozzles has been analyzed from many points of view [1-5].

The isentropic flows through conical propulsive nozzles has taken great attention under the assumptions of constant specific heats [6-9] where the method of characteristics (MOC) was successfully employed in solution technique. Also many investigators developed several numerical techniques to solve the one and multidimensional flow problems through nozzles under different operational and geometrical factors [10-14]. The accuracy of solution was a challenging criteria in such studies. 
The aim of the present work is to investigate the frozen product flows of $\mathrm{C}_{12} \mathrm{H}_{26}-\mathrm{O}_{2}, \mathrm{H}_{2}-$ $\mathrm{O}_{2}$ and $\mathrm{H}_{2}-\mathrm{F}_{2}$ reaction systems through the behavior of axisymmetric supersonic nozzles. The reaction modeling of these reaction systems has been previously studied by the present authors[15]. The method of characteristics is employed to solve the governing equations of motion under constant values of the involved controlling parameters $\left(P_{c}, \psi, \Phi, \rho_{t}\right)$. The solution technique allows the specific heat ratio, $\gamma$, to vary with temperature. The study extends to compare the obtained results of the flow field variables as well as the propulsion parameters for the three systems.

In the present study, the ambient pressure at the nozzle exit is assumed to be of zero magnitude.(i.e., the effect of the ambient pressure is neglected).

\section{EQUATIONS OF MOTION}

The problem geometry and the coordinate system as well as the nomenclatures used in the solution are depicted in Figure (1). The origin is located at the intersection of the $x$ axis with the throat plane. The x-axis is measured along the centerline of the nozzle. Using the dimensionless parameters given in the nomenclatures, the dimensionless governing equations for steady, axisymmetric, isentropic and irrotational flow through the nozzle are $[16,17]$ :

$$
\begin{aligned}
& \left(u^{2}-a^{2}\right) \frac{\partial u}{\partial x}+\left(v^{2}-a^{2}\right) \frac{\partial v}{\partial y}+2 u v \frac{\partial u}{\partial y}-\frac{a^{2} v}{y}=0.0 \\
& \frac{\partial u}{\partial y}-\frac{\partial v}{\partial x}=0.0 \\
& a=(y \cdot R \cdot T)^{1 / 2} \\
& h+\frac{u^{2}+v^{2}}{2}=H_{c} \\
& P=P_{c} e^{(\varphi-\varphi c)} \\
& \rho=P / R \cdot T \\
& M=\frac{\left(u^{2}+v^{2}\right)^{1 / 2}}{a}
\end{aligned}
$$

Equations (1) through (7) form a set of seven equations in the unknowns $u, v, a, T, p, \rho$ and $M$ respectively. Equation (5) for the pressure is obtained from the isentropic flow condition while the mole fractions remain unchanged during the expansion process [see ref. 15].

\section{CHARACTERISTIC AND COMPATIBILITY EQUATIONS}

The method of characteristics (MOC) [16-18] is employed for obtaining solutions at all points (interior as well as boundary points) in the whole solution domain. The gas dynamics and irrotationality equations (1) and (2) are replaced by the characteristic lines and compatibility equations. The characteristic line equation is:

$$
\frac{\mathrm{dy}}{\mathrm{dx}}=\frac{\mathrm{uv} \pm \mathrm{a}^{2}\left(\mathrm{M}^{2}-1\right)^{1 / 2}}{\mathrm{u}^{2}-\mathrm{a}^{2}}
$$


Referring to figures (2) and (3), the characteristic equation (8) is replaced by the following two characteristic equations (the left, l, and right, $r$, characteristics):

$(d y / d x)_{1}=\tan (\theta+\alpha)$

$(d y / d x)_{r}=\tan (\theta-\alpha)$

Where :

$$
\begin{array}{lll}
\mathrm{u}=\mathrm{V} \cos \theta & \mathrm{v}=\mathrm{V} \sin \theta ; & \theta=\tan ^{-1}(\mathrm{v} / \mathrm{u}) \\
\alpha=\sin ^{-1}(1 / \mathrm{M}) \quad \mathrm{M}=\operatorname{cosec}(\alpha) & ; \quad \cot (\alpha)=\left(\mathrm{M}^{2}-1\right)^{1 / 2}
\end{array}
$$

The corresponding compatibility equations are:

$$
\begin{aligned}
& \left(u^{2}-a^{2}\right) d u_{l}+\left[2 u v-\left(u^{2}-a^{2}\right) \tan (\theta+\alpha)\right] d v_{l}-\frac{a^{2} v}{y} d x_{l}=0 \\
& \left(u^{2}-a^{2}\right) d u_{r}+\left[2 u v-\left(u^{2}-a^{2}\right) \tan (\theta-\alpha)\right] d v_{r}-\frac{a^{2} v}{y} d x_{r}=0
\end{aligned}
$$

\section{DIFFERENCING APPROACH AND NUMERICAL TECHNIQUE}

Equations (9) through (12) are solved numerically by employing a finite difference technique at all grid points which are generated from the intersections of the $C_{1}$ and $C_{r}$ characteristics. The Euler predictor-corrector method [19] is employed for approximating the differentials of equations (9) to (12). Along the $C_{\mid}$characteristic, equations (9) and (11) take the forms:

$\Delta \mathrm{y}_{\mathrm{l}}=\lambda_{\mathrm{l}} \Delta \mathrm{x}_{\mathrm{l}}$

$\mathbf{Q}_{\mid} \Delta \mathrm{u}_{\mathrm{l}}+\mathbf{R}_{\mathbf{l}} \Delta \mathrm{v}_{\mathbf{l}}-\mathbf{S}_{\mathbf{l}} \Delta \mathrm{x}_{\mathbf{l}}=0$

where:

$\lambda_{l}=[\tan (\theta+\alpha)]_{l}$

$Q_{1}=\left[u^{2}-a^{2}\right]_{\mid}$

$\mathbf{R}_{\mathbf{l}}=\left[2 u v-\left(u^{2}-a^{2}\right) \lambda\right]_{l}$

$\mathbf{S}_{\mathrm{I}}=\left[\frac{\mathrm{a}^{2} \mathrm{v}}{\mathrm{y}}\right]_{\mathrm{l}}$

Also, equations (10) and (12) along the $C_{r}$ characteristic take the forms:

$\Delta y_{r}=\lambda_{r} \Delta x_{r}$

$\mathbf{Q}_{\mathrm{r}} \Delta \mathrm{u}_{\mathrm{r}}+\mathbf{R}_{\mathrm{r}} \Delta \mathrm{v}_{\mathrm{r}}-\mathbf{S}_{\mathrm{r}} \Delta \mathbf{x}_{\mathrm{r}}=0$

$\lambda_{r}=[\tan (\theta-\alpha)]_{r}$ 
$\mathbf{Q}_{\mathrm{r}}=\left[\mathrm{u}^{2}-\mathrm{a}^{2}\right]_{\mathrm{r}}$

$\mathbf{R}_{\mathrm{r}}=\left[2 \mathrm{uv}-\left(\mathrm{u}^{2}-\mathrm{a}^{2}\right) \lambda\right]_{\mathrm{r}}$

$\mathbf{S}_{\mathrm{r}}=\left[\frac{\mathrm{a}^{2} \mathrm{v}}{\mathrm{y}}\right]_{\mathrm{r}}$

The grid points in the solution domain consist of (see Fig. 1) four unit processes. They are the initial value points, the interior points, the axis of symmetry points; and the wall boundary points. The computational finite difference domain is shown in Fig. (4); which is bounded by the initial value line $A B$, the nozzle wall $B C D$ and the centerline of the nozzle. This computational domain consists of two regions $[8,17]$, the initial value problem region $A B F$ and the boundary value problem region $B D E F$. The inverse wall point unit process is employed for obtaining solutions in the initial value region and at point $D$ (nozzle exit lip point); whilst the direct wall point unit process is employed to obtain solutions in the boundary value problem region. Fig. (5) illustrates the unit processes for boundary points. The boundary conditions applied in the inverse wall point unit process of Fig. (5-a) are:

$\mathrm{y}_{2}=\frac{\left(\mathrm{y}_{4}-\mathrm{y}_{3}\right)}{\left(\mathrm{x}_{4}-\mathrm{x}_{3}\right)}\left(\mathrm{x}_{2}-\mathrm{x}_{3}\right)+\mathrm{y}_{3}$

$x_{S}=\rho_{t} \sin \varepsilon$

$y_{s}=1+\rho_{t}(1-\cos \varepsilon)$

$v_{S}=u_{S} \tan \varepsilon$

The direct wall points which lie on the straight wall of the nozzle shown in Fig. (5-b) are subjected to the following boundary conditions:

$\mathrm{y}_{\mathrm{S}}=1+\rho_{\mathrm{t}}(1-\cos \psi)+\left(\mathrm{x}_{\mathrm{S}}-\rho_{\mathrm{t}} \sin \psi\right) \tan \psi$

$\mathrm{v}_{\mathrm{S}}=\mathrm{u}_{\mathrm{S}} \tan \psi$

The boundary conditions along the centerline of the nozzle are $(y=V=0.0)$. The system of equations along $C_{\mid}$characteristics, equations (13) and (14) and $C_{r}$ characteristics, equations (16) and (17) are applied to obtain solutions of all interior points. The $\mathrm{C}_{\text {l }}$ characteristics equations are used to obtain location and solution at any wall point; while the $C_{r}$ characteristics equations are used to obtain solutions along the centerline of the nozzle. The coefficients appearing in the $\mathrm{C}_{\mathrm{l}}$ and $\mathrm{C}_{\mathrm{r}}$ characteristics finite difference equations are approximated by their arithmetic mean between the solution point $\mathbf{S}$ and the upstream neighboring point. Solution by MOC is started from the upstream initial value line and marching downstream up to the nozzle exit plane. Lines $A B$ and $B C$ are utilized for determining the flow field in the initial expansion region ABCG (Kernel region). The straight line CD and the characteristic line $C G$ are utilized for determining the flow properties in region CDEG. Generally, two iteration loops are performed to determine the flow variable at each grid point; the outer and inner loops. The outer loop is performed on the convergence of the static temperature, $\mathrm{T}$, which satisfied the energy equation; while the inner loop is performed on the convergence of the characteristic and compatibility equations for the same $T$ where $u, v, y, h$...etc for the three reaction systems. Results of ref. [15] are employed in the present study. 


\section{SOLUTION PROCEDURE}

The first step in generating the solution procedure is the determination of the locations as well as the properties at the supersonic initial value line $A B$ shown in Fig. (4) for given values of the controlling parameters. The Kliegel method [20], the contour proposed by Saur [16]; and the $x-y$ relation of the initial data points given by Hoffman [8] are employed for this purpose for each fuel-oxidizer system. This solution is accomplished by simple iterative technique for the outer and inner loops as mentioned before. Then, the overall solution procedure proceeds as follows. The fuel-oxidizer system is selected; and the controlling values are chosen $\left(\Phi=1, P_{c}=30, \psi=20^{\circ}\right.$ and $\left.\rho_{\mathrm{t}}=2\right)$. The MOC is applied to the suitable unit process at the corresponding grid points in the solution domain. At this stage, all flow properties are determined and the solution proceeds to calculate the different propulsion parameters. It should be mentioned here that the MOC has been proven to be the most accurate method for predicting the flow behavior in the supersonic region of the nozzle, since the equations are of hyperbolic type[18].

The regulation of grid spacing is such that very small grid sizes are used in the initial value region due to large gradients in the flow properties in this region. Eleven initial data points $(\Delta y=0.1)$ are assigned along the initial value line; with $\Delta \varepsilon=1^{\circ}$ along the arc of the nozzle throat. The corresponding points of the initial region ABF are 121 points; while the numbers of grid points influenced by the arc (region BCGF) are 393 points. Beyond the initial region, the grid spacing are gradually increased. A total equal numbers of $(10+\psi) C_{r}$ and $C_{l}$ characteristics are generated in the region $A B C G$. It should be pointed that the chosen grade regulations are selected after several numerical experimentations for the sake of maximum accuracy of results

\section{PROPULSION PARAMETERS}

After solution is attained for the axisymmetric nozzle, the important parameters for the propulsive nozzle are calculated. These parameters are the mass flow rate, $\mathrm{m} \cdot$, the thrust, $F$, the specific impulse, $I_{s p}$, the specific impulse based on fuel consumption, $I_{s p, f}$ and the thrust efficiency $\eta_{\mathrm{f}}$. The thrust efficiency requires the solution of the in hand problems on the one dimensional (OD) basis. The latter case was carried out by the same procedure given in [21] and the definitions for $\mathrm{m} \cdot$ and $\mathrm{F}$ given by [16] since $\mathrm{Hc}, \mathrm{h}$, $\Phi, R, m$...etc are kept unchanged for both axisymmetric and one dimensional flow equations.

The dimensionless mass flow rate for the axisymmetric flow is determined by integrating the mass flux crossing the initial value line, $A B$, where $(v \approx 0.0)$ and the mass

flux is $\left(\bar{m}^{\cdot}=\int_{0}^{y t} 2 \pi \bar{\rho} \bar{u} \bar{y} \overline{d y}\right)$, the result is:

$\mathrm{m}^{*}=2 \int_{0}^{1} \rho \mathrm{u} y \mathrm{dy}$

Simpson one-third rule is used for calculating the integral of equation (25). Following the definition of the nozzle thrust force given by [8], the dimensionless thrust $F$ is given by: 
$F_{i}=2 \int_{0}^{1}\left[\left(P-P_{a}\right)+\rho u^{2}\right] y d y+\left[y_{w, i-1}\left(P_{i-1}-P_{a}\right)+y_{w, i}\left(P_{i}-P_{a}\right)\right]\left(y_{w, i}-y_{w, i-1}\right)$

The integral in equation (26) for $(i \geq 1)$ is performed along the initial value line only by using Simpson one-third rule.

The specific impulse is given by:

$\mathrm{I}_{\mathrm{sp}}=\mathrm{F} / \mathrm{m}^{*}$

$I_{s p, f}=F /\left(f . m^{*}\right)$

Where $f$ in equation (28) represents the ratio between fuel mass flow rate, $\mathrm{m}^{\circ}$, and total mass flow rate, $m^{*},\left(f=m^{*} / m^{*}\right)$. The thrust efficiency is given by:

$\eta_{\mathrm{f}}=\mathrm{F} / \mathrm{F}_{\mathrm{OD}}$

The mass flow rates of the three fuel oxidizer systems are calculated by referring to the reaction equations for these systems given in ref. [15]. The result is:

$$
\begin{array}{ll}
f=\frac{\left.n \bar{m})_{C}+n \bar{m}\right) H_{2}}{\left.\left.n \bar{m})_{C}+n \bar{m}\right) H_{2}+\bar{m}\right) O_{2}\left(\frac{2 n+m / 2}{\Phi}\right)} & \text { for }\left(\mathrm{Cn} \mathrm{Hm}-O_{2}\right) \text { system } \\
f=\frac{2 \bar{m}) H_{2}}{\left.2 \bar{m}) H_{2}+\frac{1}{\Phi} 2 \bar{m}\right) O_{2}} & \text { for } \mathrm{H}_{2}-O_{2} \text { system } \\
f=\frac{\bar{m}) H_{2}}{\left.\bar{m}) H_{2}+\frac{1}{\Phi} \bar{m}\right) F_{2}} & \text { for } \mathrm{H}_{2}-F_{2} \text { system }
\end{array}
$$

\section{RESULTS AND DISCUSSIONS}

The present numerical scheme is employed to solve the in hand problem of the flow of product gases of $\mathrm{C}_{12} \mathrm{H}_{26}-\mathrm{O}_{2}, \mathrm{H}_{2}-\mathrm{O}_{2}$ and $\mathrm{H}_{2}-\mathrm{F}_{2}$ reactions systems through supersonic propulsive nozzles. For simplicity, these three reaction systems will be referred to system (I), (II) and (III) respectively in the following discussions. The validity of this scheme is tested by comparing some of the present results with the closest and available published ones; where suitable approximations to some parameters ( $\gamma$ for example) are possible. Therefore, comparison of the present results is limited to system III and system I where results for $\gamma \approx 1.4$ and 1.2 respectively are available for constant $\gamma$ flows. Fig. (6) depicts the experimental results of ref. [17] and the present results. As shown from Fig. (6), fairly good agreement is observed taking into consideration that the gas constant for experiments is $0.287 \mathrm{~kJ} / \mathrm{kg}$.K whilst its average value for system III is $0.496 \mathrm{~kJ} / \mathrm{kg} . \mathrm{K}$; and one might expects no better agreement. A more reasonable comparison between the present results and the theoretical results of Hoffman [8] and El-Kady [22] is shown in Fig. (7) for system I. Since the gas constants used are nearly equal $(0.337 \mathrm{~kJ} / \mathrm{kg} . \mathrm{K}$ in the present calculations, and $0.320 \mathrm{~kJ} / \mathrm{kg} . \mathrm{K}$ for [8] and [22]), it is noticed that there are very good agreement for $\mathrm{P}$ and $\mathrm{M}$ profiles; and good agreement for $\mathrm{T}$ profiles. Such difference in agreement of the $\mathrm{P}, \mathrm{M}$ and $\mathrm{T}$ profiles was also 
recorded in the work of Nakahashi [23] and Stiles [24] when compared their results with constant $y$ flows. Thus, the accuracy of the present obtained results are accepted and the present numerical scheme is reliable.

The present obtained results of $T, P, V$ and $M$ profiles for the three reaction systems product flows are shown in figures (8) to (11) respectively. Only variations of the mentioned flow parameters along the nozzle wall $(\mathrm{w})$ and centerline $(\mathrm{CL})$ are drawn; representing the extreme values of the parameters. As shown from Fig. (8) and (9) the profiles of T and P coincide for systems I and II. The reason of this result is attributed to the closeness values of the adiabatic flame temperatures for both systems [15]. On the other hand, obtained values of $\mathrm{T}$ and $\mathrm{P}$ as predicted by system III are different from those of systems I and II. In the throat region one can easily see that $T_{\text {III }}$ is higher than $T_{\mid}$and $T_{\| I}$; while $P_{\| I}$ is lower than $P_{\mid}$and $P_{\| I}$. The results of Figures (8) and (9) indicate that the rate of expansion of system III is higher than that of the other two systems.

Investigating the velocity profiles of Fig. (10), one observes that the highest values are those of system III and the lowest are of system I. It is also observed that although the temperature and pressure profiles of systems I and II coincide, the velocity profiles are deviated from each other. This deviation comes from the fact that the enthalpy drop $\left(\mathrm{H}_{\mathrm{c}}-\right.$ h) based on mass bases for system II is of higher magnitudes than that for system I since $m_{\|}<m_{\mid}$[15]; and this results in $V_{\|}>V_{\mid}$at all $x$-locations. Fig. (10) indicate also that $V_{\text {II }}$ becomes closer to $V_{\text {III }}$ as the flow moves downstream which means that $V_{\text {II }}$ is more sensitive to the difference $(\mathrm{Hc}-\mathrm{h})$ than $\mathrm{V}_{\mathrm{III}}$. The Mach number profiles shown in Fig. (11) indicate that all $M$ values are nearly the same in throat region; and downstream of the throat region $M_{\| I}$ deviates to higher values from $M_{l}$ and $M_{\|}$which coincide in whole flow field. The presented $M$ profiles may be explained as follows: equation (7) shows that $M$ is proportional to $V$ and $(m)^{1 / 2}$ while it is inversely proportional to $T^{1 / 2}$ and $\gamma^{1 / 2}$. Now by examining the velocity profiles and putting in mind that the molecular weights $m_{1}>m_{\|}$, $\mathrm{T}_{\mathrm{Cl}} \approx \mathrm{T}_{\mathrm{cll}}$; the result is $\mathrm{V}_{\| \mid}\left(\mathrm{m}_{\|}\right)^{1 / 2} \approx \mathrm{V}_{1}\left(\mathrm{~m}_{1}\right)^{1 / 2}$ which yield $\mathbb{M}_{1}=\mathrm{M}_{\| \mid}$. By comparing the properties $(\nabla, T, m$ and $\bar{Y})$ for systems I and III and at high values of $x$ one can notice that $M_{I I I}$ is higher than $\mathrm{M}_{1}$.

Figures (8) to (11) show that the behavior of the flow properties along the wall are characterized by a discontinuity point. On the other hand this behavior along the centerline is characterized by the formation of an oblique shock wave. At the point of tangency (point c of Fig. 4), there is a discontinuity in the curvature of the wall which generate a weak compression wave which causes this discontinuity in the flow properties. This formed compression wave propagates into the flow field causing the characteristic lines to coalesce in the neighbors of line CG forming waves which become of more steepness in the direction of point $\mathrm{G}$ and form an oblique shock wave of maximum strength at the centerline.

In the throat region, the high turning of the curved wall causes the gases to expand by higher rates at the wall as compared with its expansion at the centerline. Such difference in the rates of expansion yields lower values of $T, P$ and higher values of $V$ and $\mathrm{M}$ at the wall as compared with their corresponding values at the centerline at the same $x$-location till the intersecting point $(x \approx 3)$. Between the point of intersection and the shock wave this trend is reversed. Behind the shock wave and due to its formation, the relative magnitudes of the flow properties are reversed again to take their original forms of the throat region. 
A comparison between the nozzle propulsive parameters $\left(F, I_{s p}, I_{s p, f}\right.$ and $\left.\eta_{f}\right)$ is illustrated in Fig. (12) for the three fuel-oxidizer systems. From Fig. (12-a), it is noticed that $F$ increases with $\mathrm{x}$ by high rate at moderate values of $\mathrm{x}$; and low rate at small and high values of $x$. Fig. (12-a) also indicates that the profile of the thrust developed by system III, is deviated from those developed by the two other systems; being of higher magnitudes at small values of $x$ while it becomes of lower magnitudes at high values of $x$. The reason for this behavior is attributed to the fact that at relatively small values of $x$ , $V_{I I I}>V_{||}>V_{1}$ which causes the momentum thrust component of $F(m \vee V)$ to be dominate near the throat region and consequently $F_{I I I}$ is higher than those of system I and II at that region. As $x$ increases $(x>1)$, the pressure force component of the thrust causes the developed forces of systems I and II to be higher than that of system III. The results shown in Fig. (12-a) lead to the conclusion that if high thrust is required the $\mathrm{C}_{12} \mathrm{H}_{26}-\mathrm{O}_{2}$ or $\mathrm{H}_{2}-\mathrm{O}_{2}$ systems are recommended over the $\mathrm{H}_{2}-\mathrm{F}_{2}$ system.

Figures (12-b) and (12-c) present the profiles of the specific impulse, $I_{s p}$, based on total mass flow rate and that based on fuel flow rate, $I_{s p, f}$, respectively. These figures indicate that the profiles of $I_{s p}$ and $I_{s p, f}$ for system (I) and (II) do not coincide although $F$ developed by the two systems is the same; which means that $\mathrm{m}^{{ }^{\prime}}$ and $\mathrm{m}^{\prime}$ " has different values $\left(m^{*}>m^{*}{ }_{\mid l}\right.$ and $\left.m_{f, l}{ }_{f,}>m^{*}, \|\right)$. Besides, the $H_{2}-F_{2}$ system has the highest values of $I_{s p}$ and for $x \geq 10$, both $\mathrm{H}_{2}-\mathrm{F}_{2}$ and $\mathrm{H}_{2}-\mathrm{O}_{2}$ systems yield equal values of $I_{\mathrm{sp}}$. Thus if the thrust per unit mass of fuel and oxidizer is dominating for the purpose of weight, $\mathrm{H}_{2}-\mathrm{F}_{2}$ and $\mathrm{H}_{2}-\mathrm{O}_{2}$ systems are recommended to be used. On the other hand as shown from Fig. (12-c), if the thrust per unit mass of fuel is important for the purpose of cost, the $\mathrm{H}_{2}-\mathrm{F}_{2}$ system is recommended to be employed.

Figure (12-d) shows that there is no nearly effect of the three reaction systems on the thrust efficiency. Also, this figure indicate that the thrust force obtained from two dimensional flow solution is nearly equal to that obtained from one dimensional flow solution.

\section{CONCLUSIONS}

The frozen flow of the gas products of $\mathrm{C}_{12} \mathrm{H}_{26}-\mathrm{O}_{2}, \mathrm{H}_{2}-\mathrm{O}_{2}$ and $\mathrm{H}_{2}-\mathrm{F}_{2}$ reaction systems is investigated. The governing equations for the flow through supersonic propulsive nozzles are solved by the method of characteristic. The following are the most important conclusions:

1. The discontinuity in the wall curvature of the nozzle between the throat circular arc and the straight wall generates compression waves which cause oblique shock waves in the flow field.

2. The flow properties are of two dimensional nature in the Kernel region. Downstream of the Kernel region the flow properties are of one dimensional type; but the propulsive parameters are of two dimensional nature in the whole flow field.

3. The expanded gases produced by system I and II follow the same behavior and the values of $T, P$ and $M$ are nearly equal for both systems. The gases produced by system III are expanded by higher rates; causing the shock wave to delay and to increase $\mathrm{M}$ or decrease $\mathrm{T}$ and $\mathrm{P}$.

4. The thrust efficiency is not influenced by the investigated reaction systems. 


\section{REFERENCES}

1. Papamoschou, D. and Zill , A. , "Fundamental Investigation of Supersonic Nozzle Flow Separation" , AIAA paper 2004 - 1111 , Jan. 2004.

2. Romine , G. L. , "Nozzle Flow Separation" , AIAA Journal , vol. 36 , No 9 , p 1618 $-1625,1998$.

3. Deck , S. , Hollard , R. and Guillen , Ph. "Numerical Simulation of Steady and Unsteady Separated Nozzle Flows" , AIAA paper 2002 - 0406 , 2002.

4. Hasen , G. A. , "Navier-Stokes Solutions for An Axisymmetric Nozzle" , AIAA Journal, Vol. 20 , No . 9 , Sep. 1982.

5. A. G. Kuzm'in , "Boundary-Value Problems for Transonic Flows", John Wiley \& Sons , 2002.

6. Migdal , D. , and Landis , F. "Characteristics of Conical Supersonic Nozzles" , Journal of The American Rocket Society, Vol. 32 , No. 12 , Dec. 1962.

7. Migdal , D. , and Kosson , R. "Shock Predictions in Conical Nozzles" , AIAA Journal, Vol. 3 , No. 8 , August 1965.

8. Zucrow , M. J. , and Hoffman , J. D. "Gas Dynamics" , Vol. II , John Wiley and Sons, New York, 1977.

9. Kemry , M. M. "Geometrical Factors Influencing The Flow Field in A Propulsive Nozzle" , Third Int. Conf. of Fluid Mechanics , Cairo , 1990.

10. Frey , H. M. , Kliegel , J. R. , and Tyson , T. J. "ICRPG One-Dimensional Kinetic Nozzle Analysis Program", Dynamic Science, Monrovia , Calif , July 1968.

11. Gordon , S. , and Mcbride , B. J. "Computer Program for Calculation of Complex Chemical Equilibrium Compositions, Rocket Performance, Incident and Reflected Shocks, and Champman-Jougnet Detonations" , NASA SP-273 , 1971.

12. Westenberg, A. A. , and Favin , S. "Complex Chemical Kinetic in Supersonic Nozzle Flow" . 12 ${ }^{\text {th }}$ Symp. (Int) on Combustion, 1969.

13. Sultan , K. M. "A Study of Combustion and Fluid Dynamics in Liquid Propellant Rocket Engine" , MS.C Thesis, Grayounis University , Benghazy , Libya , 1995.

14. Anderson Jr , J. D. "A Time Dependent Analysis for Vibrational and Chemical Nonequilibrium Nozzle Flows", AIAA Journal , Vol. 8 , No. 3 , March 1970.

15. Kemry, M. and El-Kady , E. A. , "A Theoretical Study on Hydrocarbon-Oxygen and Hydrgen-Florine Reaction Systems", Journal of Al Azhar University ,Engineering Sector (JAUES), vol. 3 Number 7 , 2008.

16. Zucrow, M. J. , and Hoffman , J. D. , "Gas Dynamic" , Vol. 1 , John Wiley and Sons, New York, 1977.

17. Anderson Jr , J. D. , "Modern Compressible Flow" , $2^{\text {nd }}$ Ed. , McGraw Hill , New York , 1990.

18. Cline M. C. , and Hoffman , J. D. "Comparison of Characteristic Schemes for Three-Dimensional , Steady, Isentropic Flow" , AIAA Journal, Vol. 10 , No. 11 , Nov. 1972.

19. Gerald , C. F. , "Applied Numerical Analysis" , $2^{\text {nd }}$ Ed. Addison-Wesley , Massachusetts , 1978.

20. Kliegal , J. R. , and Levine, J. N. "Transonic Flow in Small Throat Radius of Curvature Nozzles", AIAA Journal, Vol. 7 , No. 7 , July. 1969.

21. Kemry, M. M. , El-Kady, M. A. and Abdel Aal, M. "Study of The Expansion of Hydrocarbon Oxygen Products Through Supersonic Nozzles" , Third ASAT Conference, PP293-305, Cairo , 1989.

22. El-Kady , M. A. , "Prediction of The Flow Variables for An Axisymmetric Supersonic Nozzle of Various Contours" , Conf. of Mech. Eng. , $10^{\text {th }}$ Ramadan City, Egypt , 1989. 
23. Nakahashi, K. "An Implicit Finite-Difference Method for Chemical Non-equilibrium Flow Through an Axisymmetric Supersonic Nozzle" , Tans. Japan Soc. Aero , Space Sci , Vol. 25 , No. 69 , Nov. 1982.

24. Stiles, R.J. , and Hoffman, J. D. "Analysis of Steady, Two-Dimensional , Chemically Reacting , Non-equilibrium , Inviscid Flow in Nozzles" , AIAA Journal , Vol. 23 , No. 3 , March 1985.

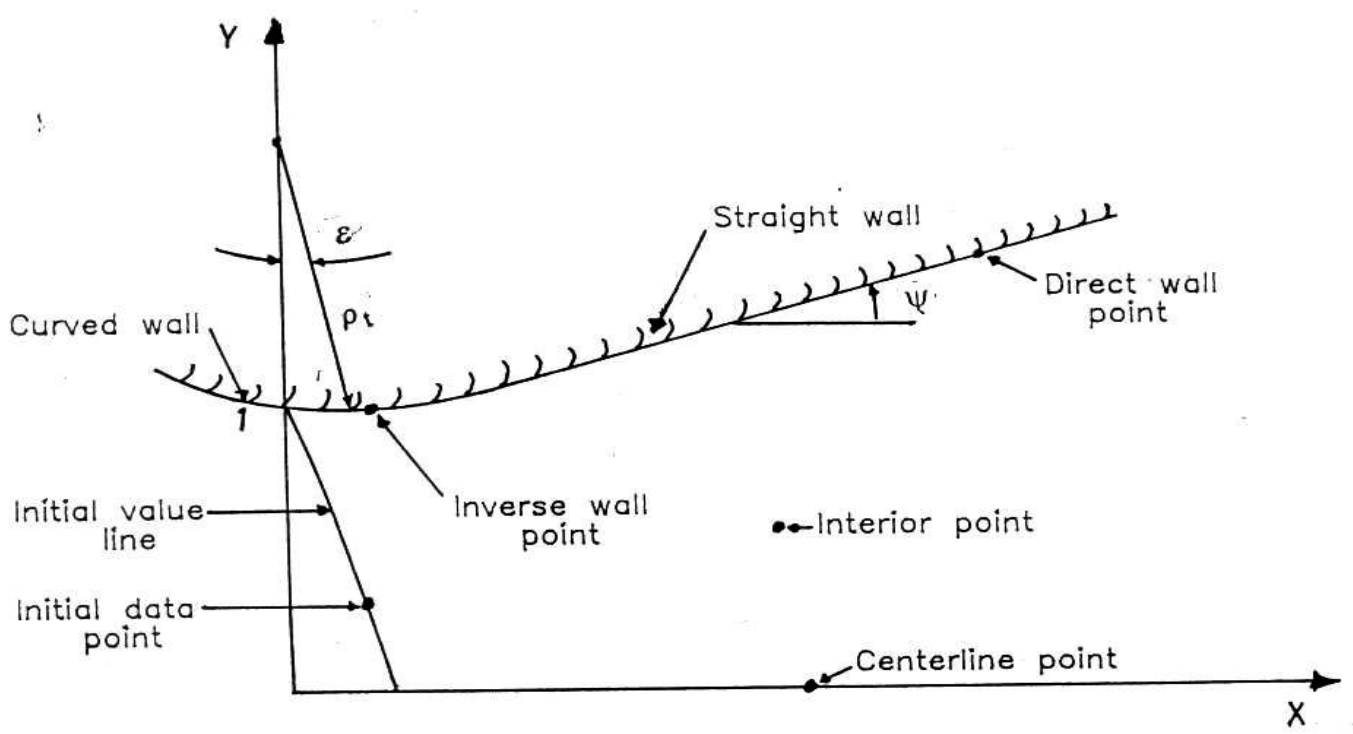

Figure (1) Nozzle geometry and flow field unit processes

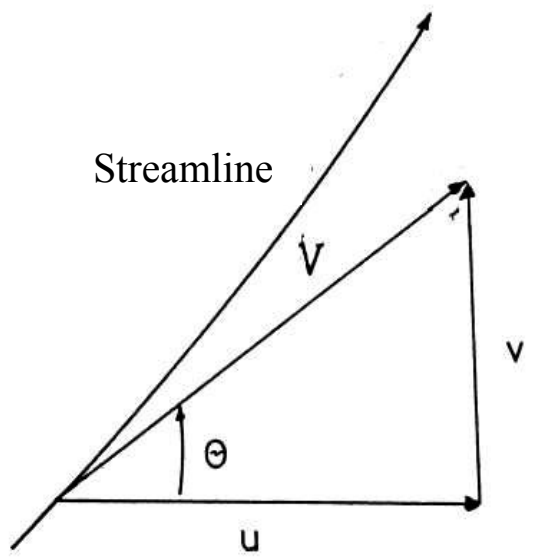

(a) Relation between the flow angle $\theta$ and the velocity component $u$ and $v$

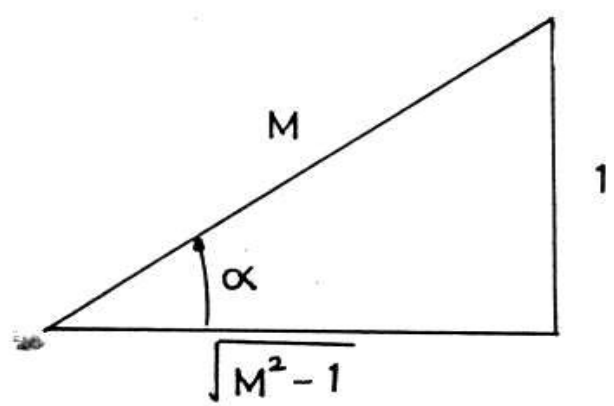

(b) Relation between the Mach angle $\alpha$ and the Mach number

Figure (2) Relationship between the flow angle $\theta$, the Mach angle $\alpha$, and the physical properties 


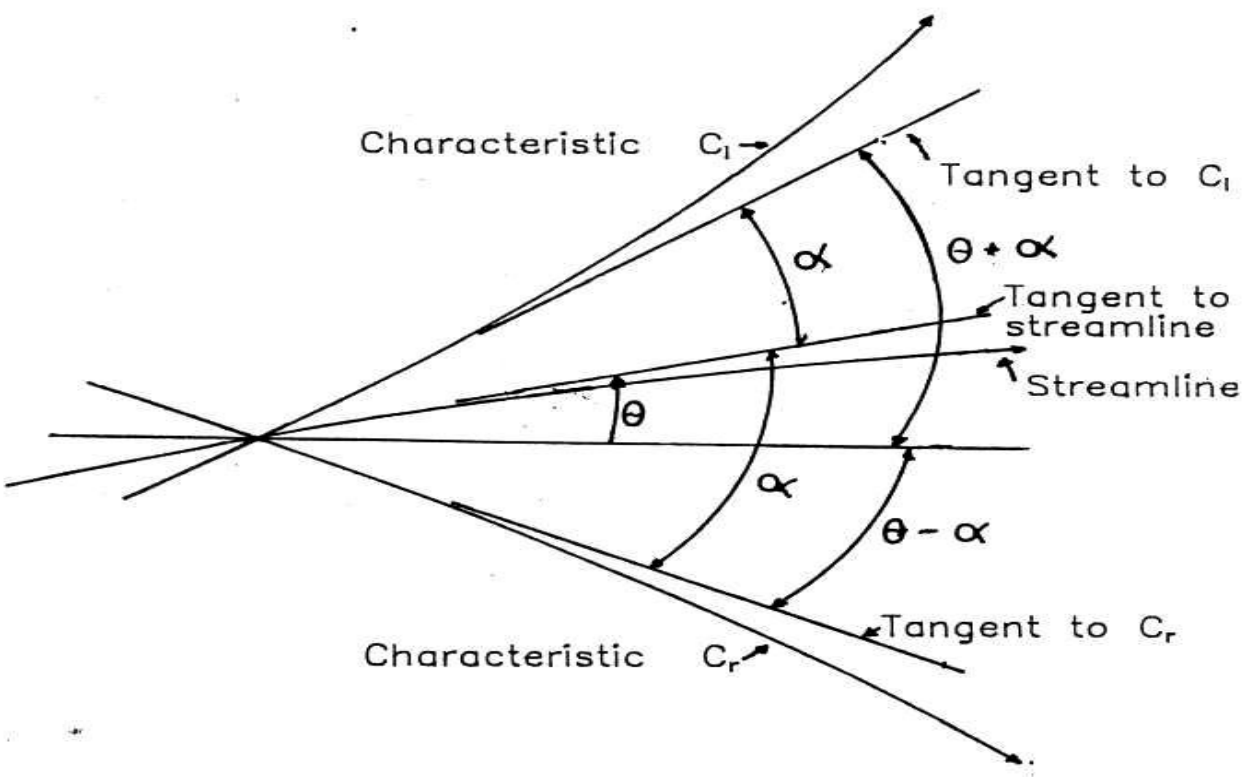

Figure (3) Illustration of the characteristics $C_{I}$ and $C_{r}$ (Mach lines) and the streamline in the physical space

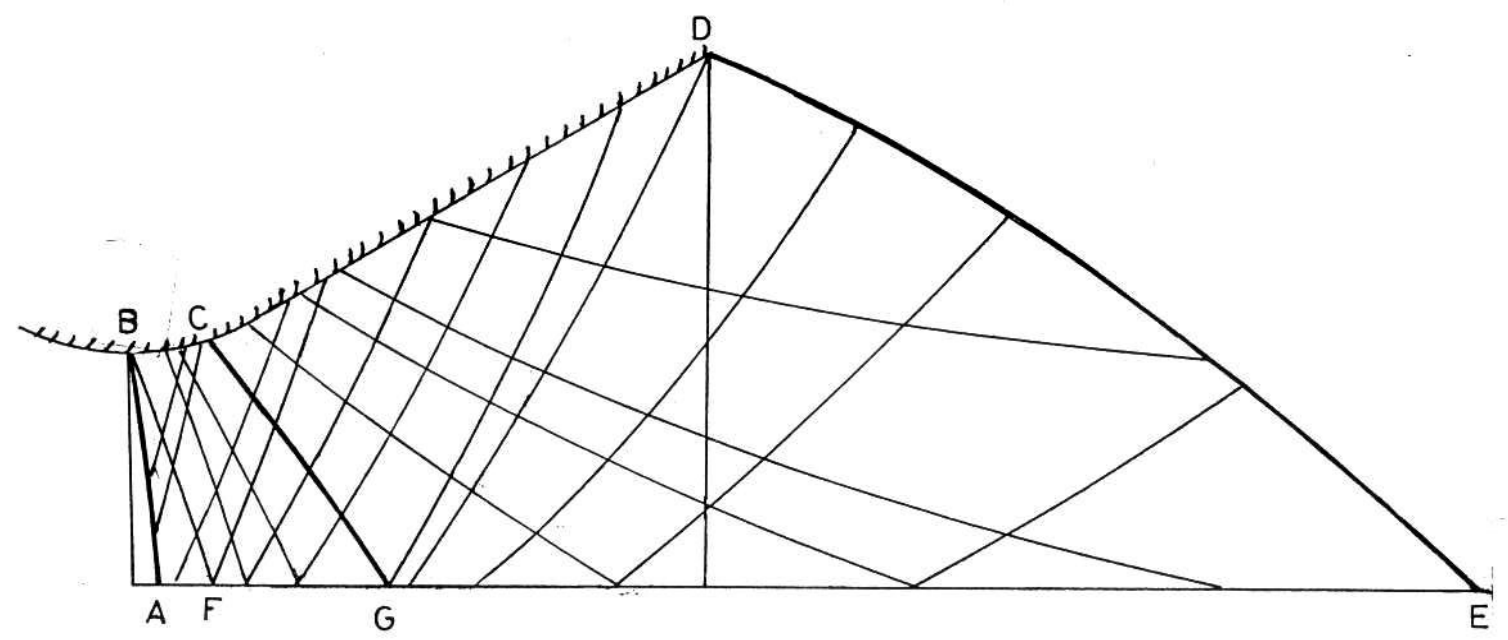

Figure (4) Finite-difference network for the whole flow field

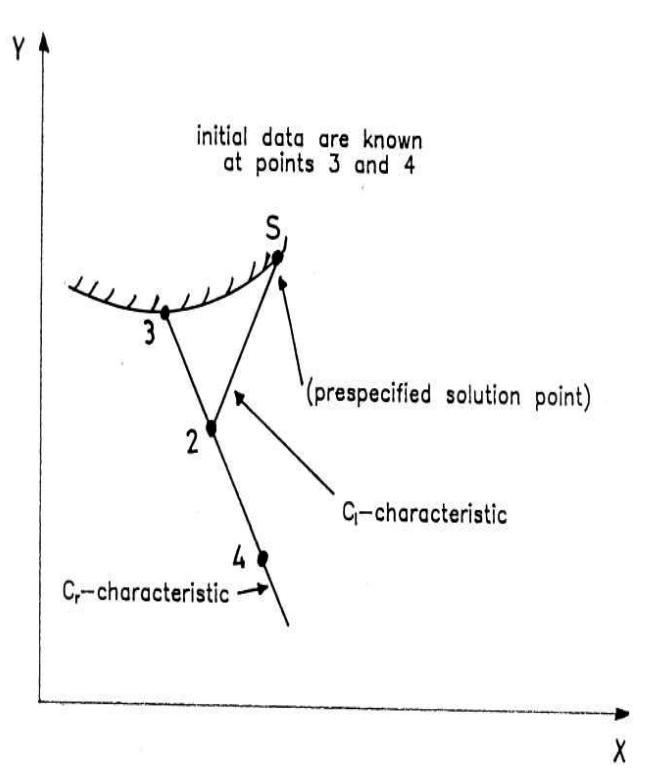

(o) Inverse wall point

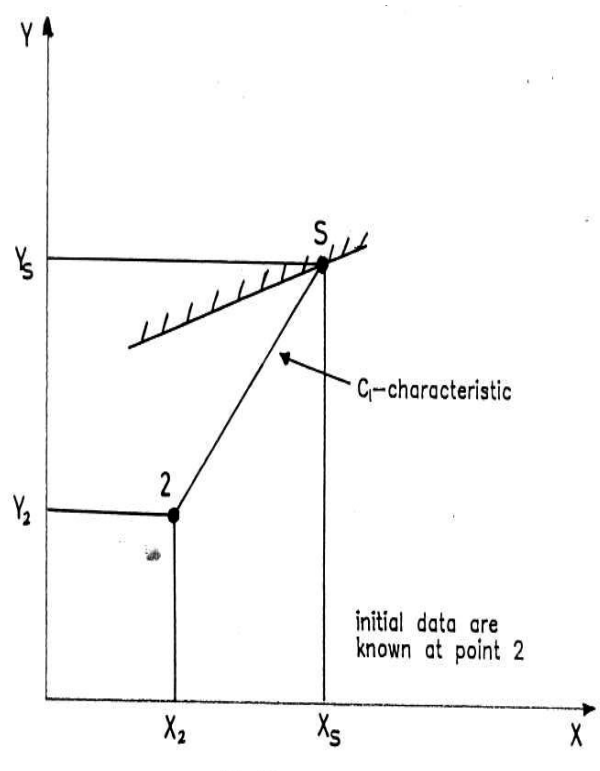

(b) Direct wall point 


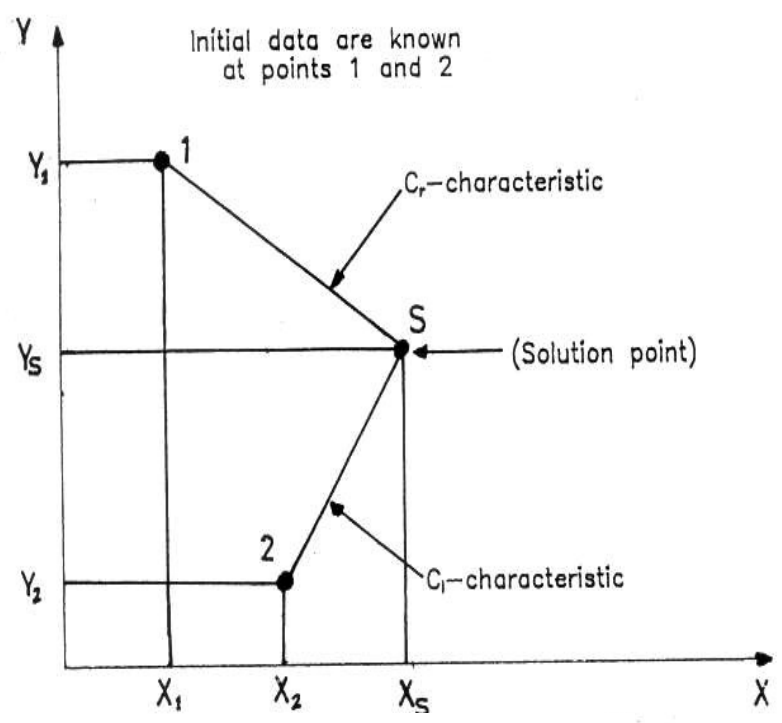

(c) Interior point

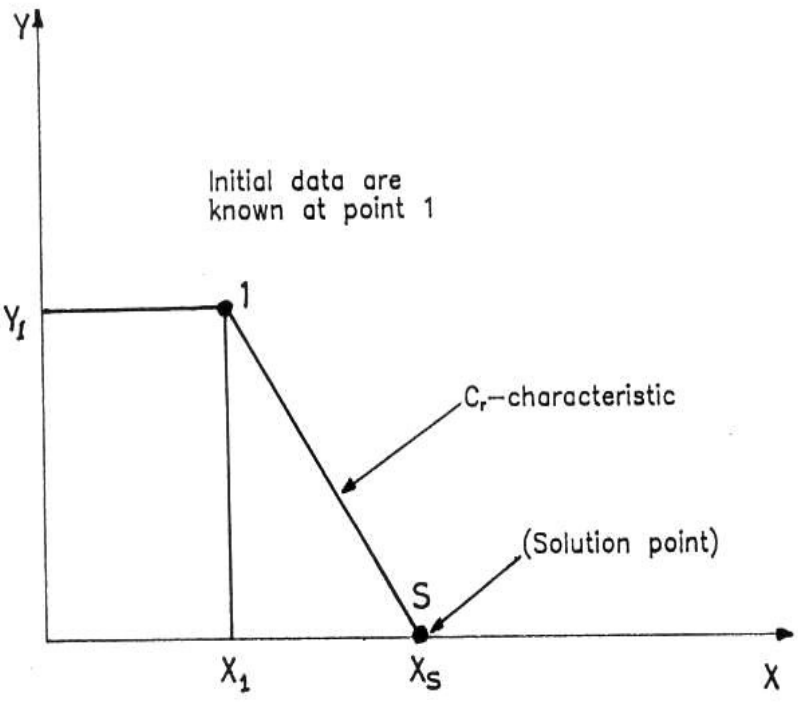

(d) Centerline point

Figure (5) Unit processes for the solution domain

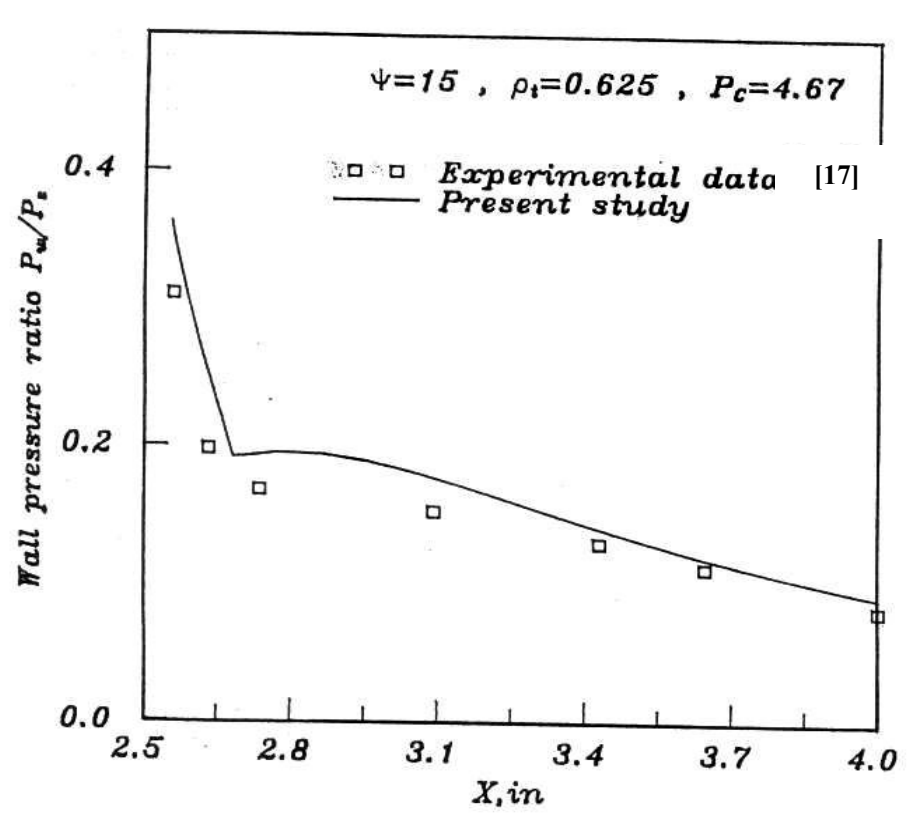

(a) Wall pressure

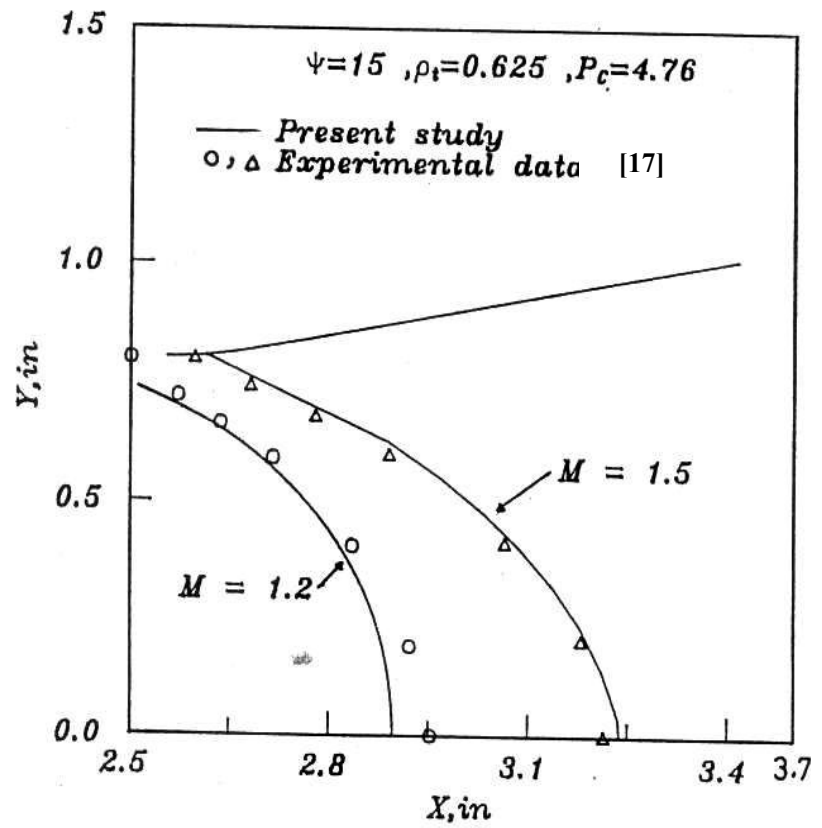

(b) Mach number contours

Figure (6) Results of $\mathrm{H}_{2}-\mathrm{F}_{2}$ system compared with $Y=1.4$ experimental results 


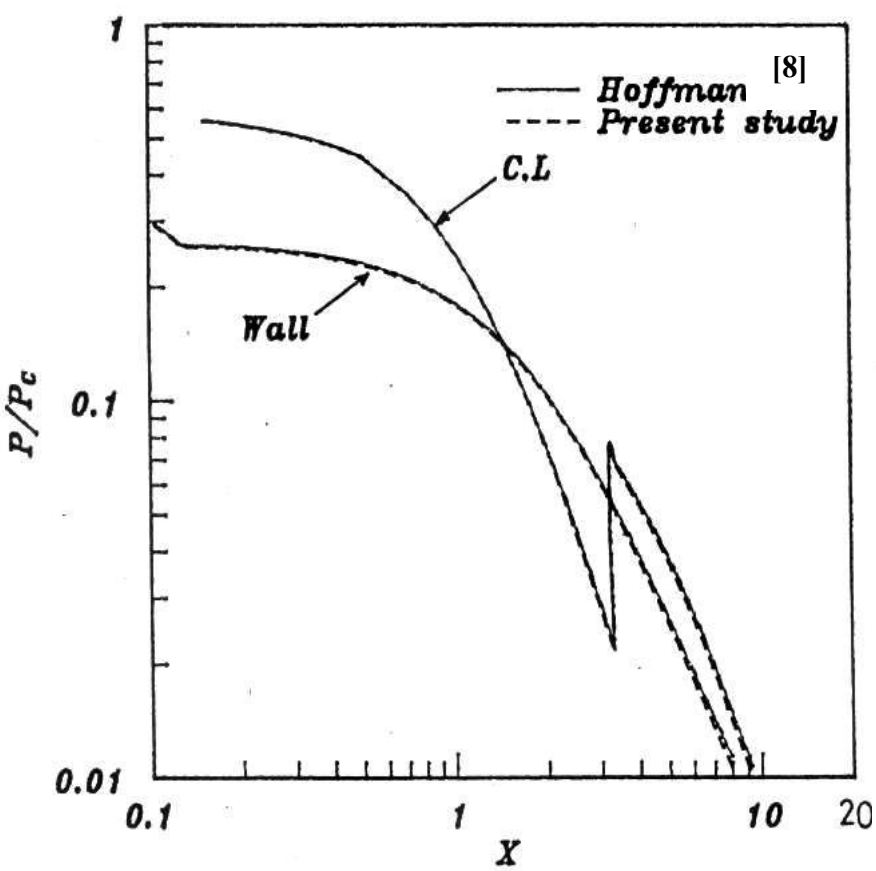

(a) $\rho_{\mathrm{t}}=0.5, \psi=15$

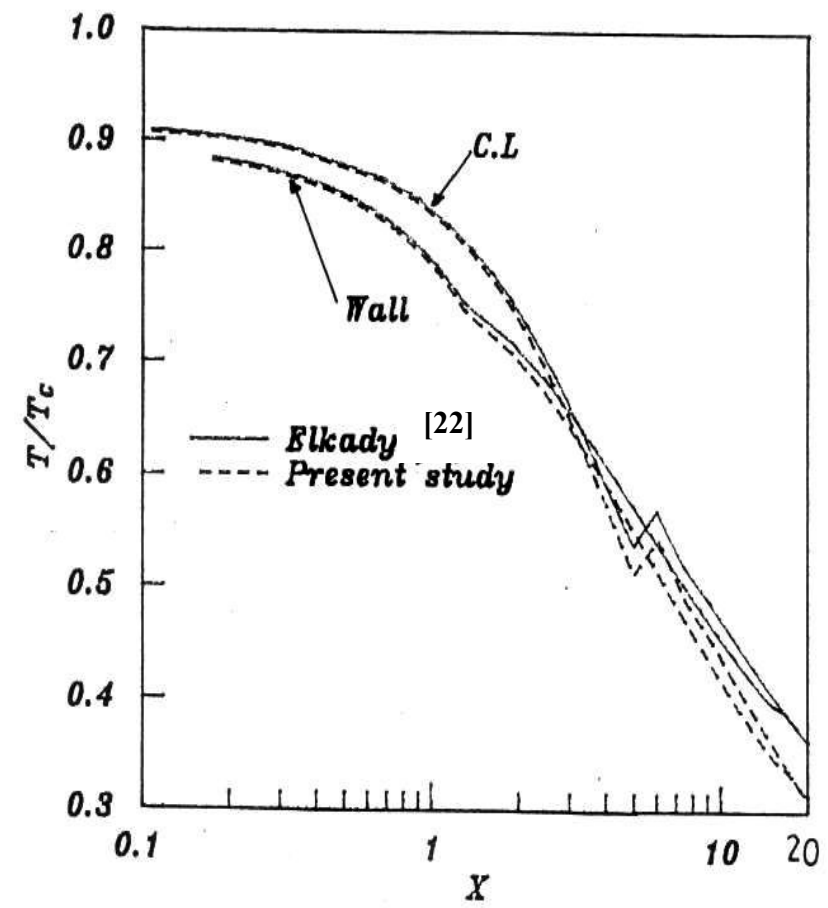

(ii) Temperature rotio

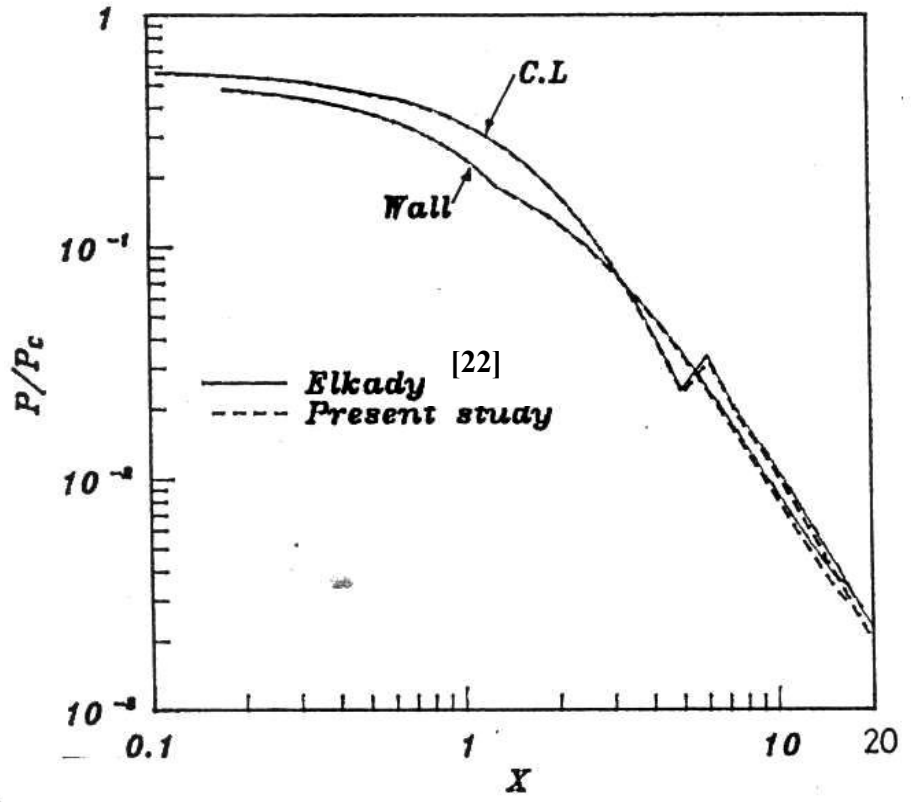

(i) Pressure ratio

(b) $\rho_{\mathrm{t}}=5, \psi=15$

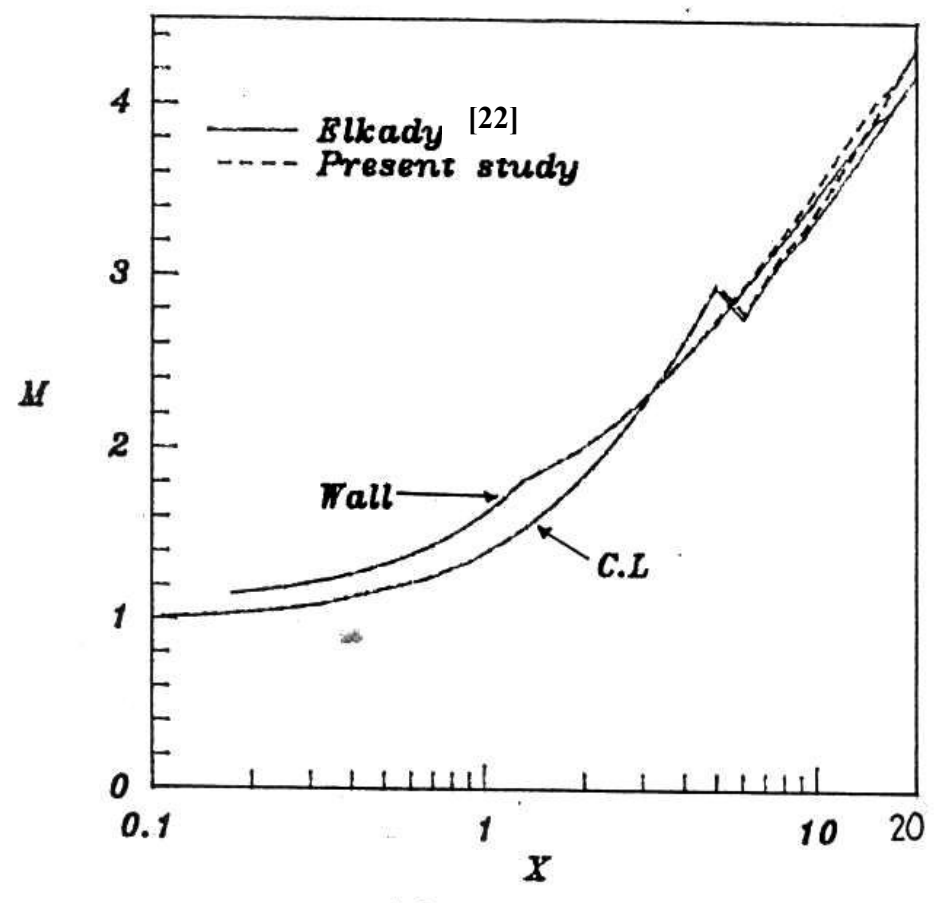

(iii) Mach number

Figure (7) Results of $\mathrm{C}_{12} \mathrm{H}_{24}-\mathrm{O}_{2}$ system compared with $\mathrm{y}=1.2$ theoretical results. 


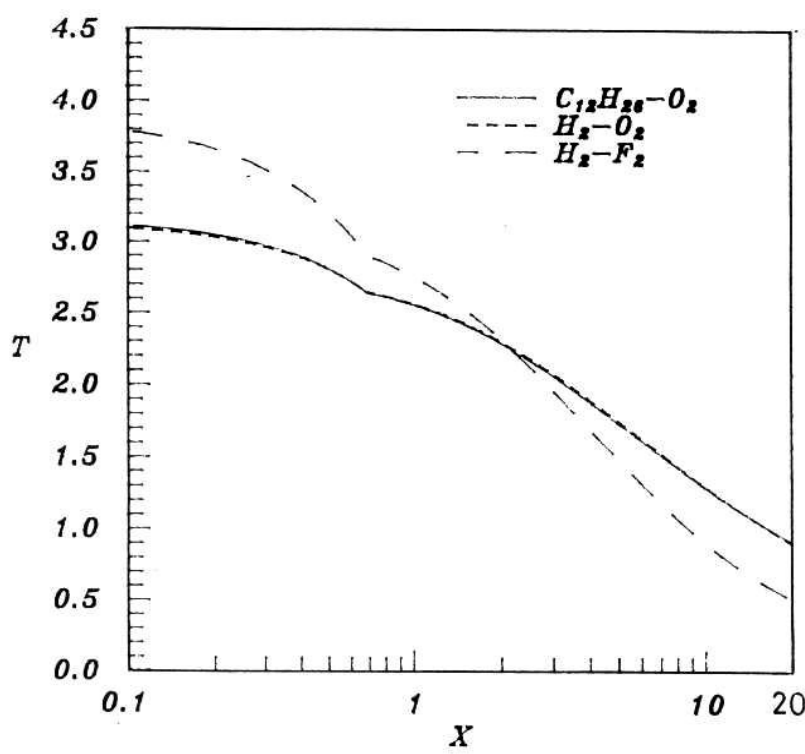

(i) Wall

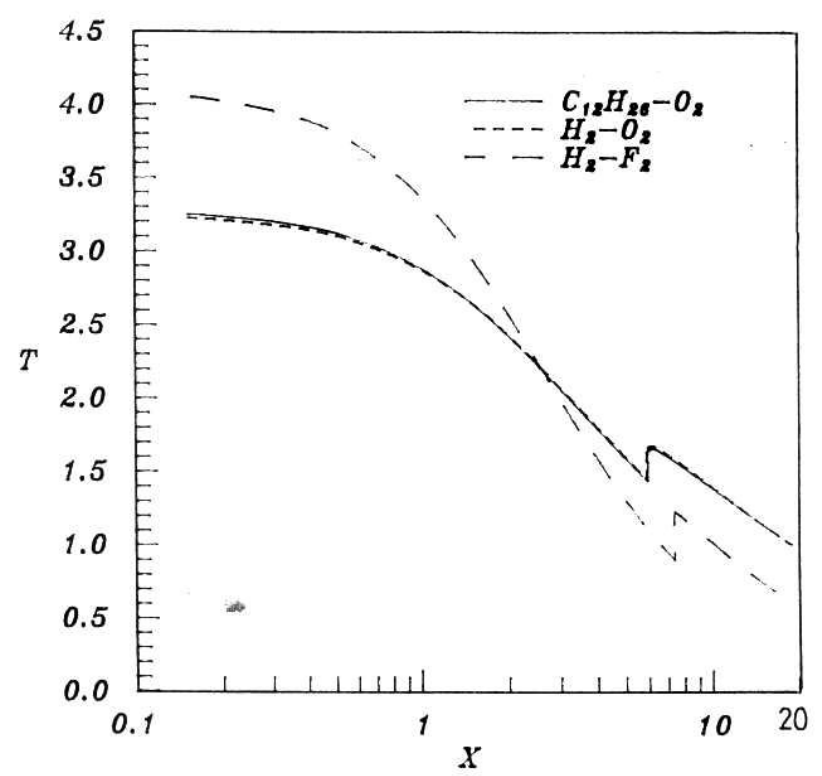

(ii) Centerline

Figure (8). Comparison of the flow temperature as predicted by the three fuel-oxidizer systems.

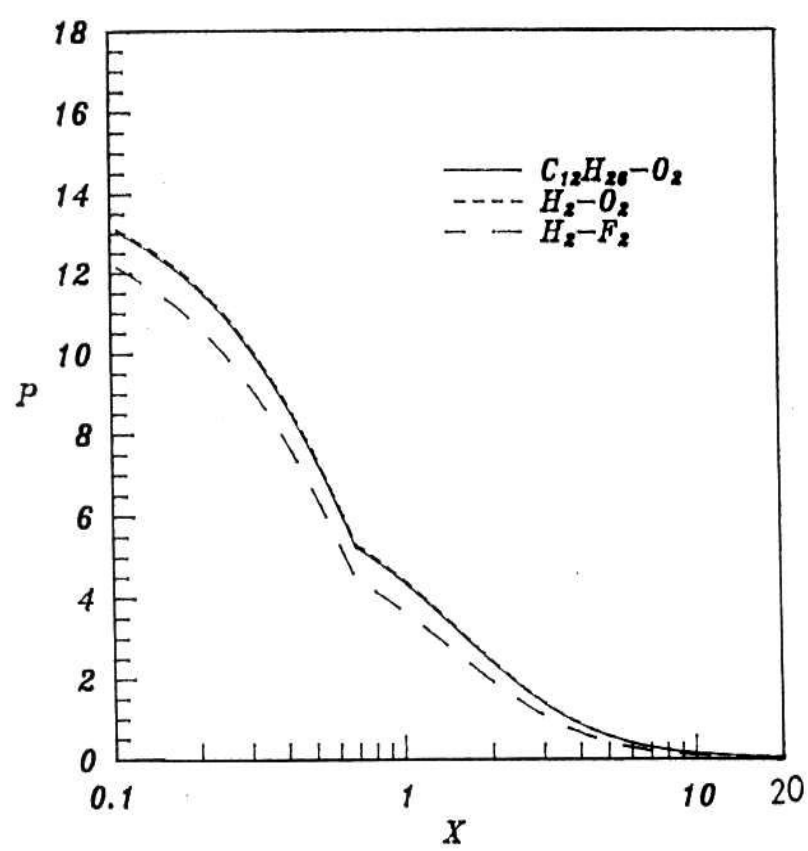

(i) Wall

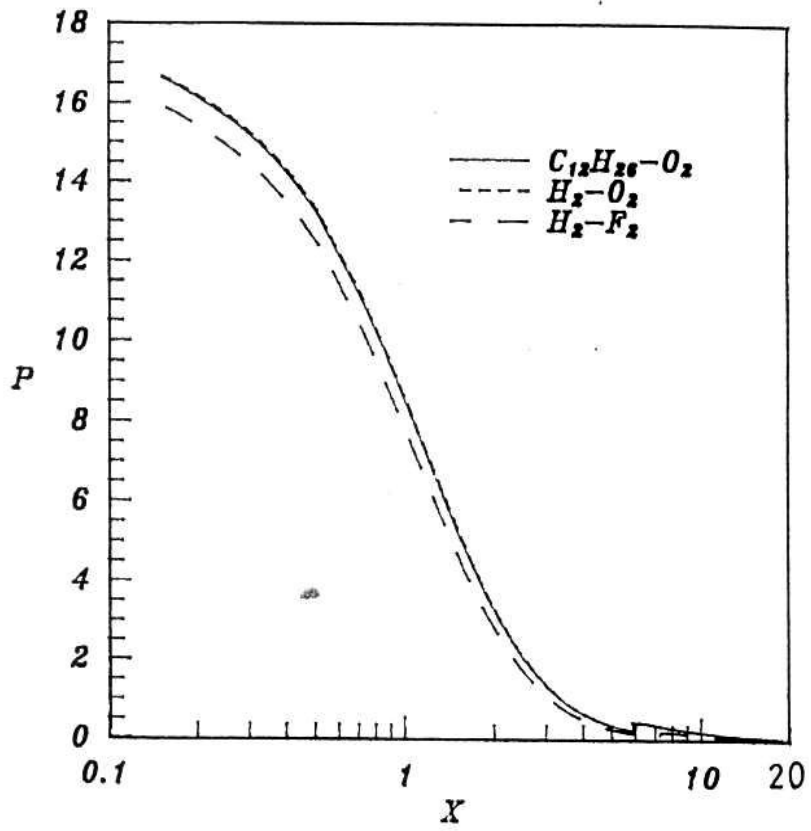

(ii) Centerline

Figure (9). Comparison of the flow pressure as predicted by the three fuel-oxidizer systems. 

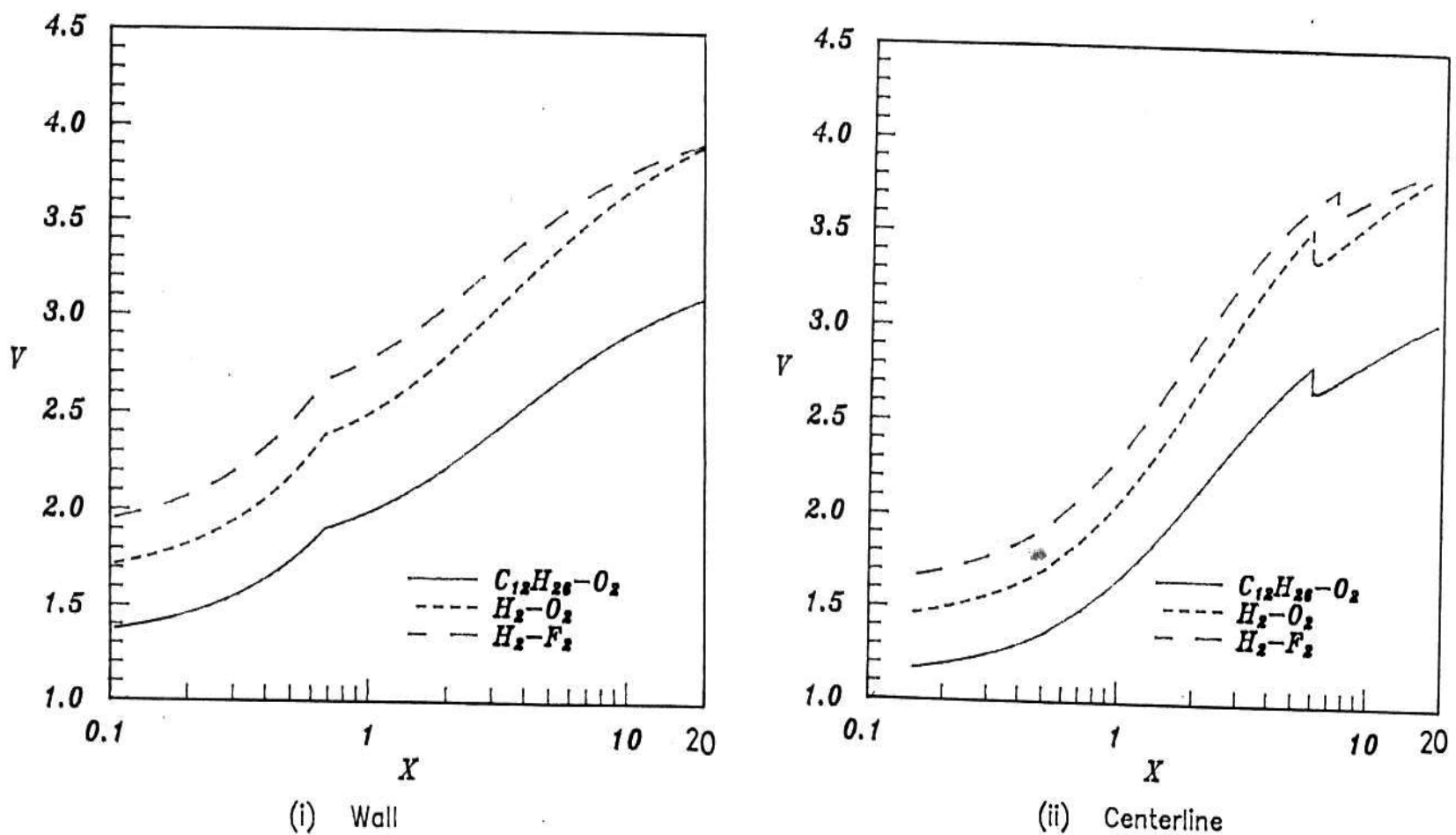

Figure (10). Comparison of the flow velocity magnitude as predicted by the three fuel-oxidizer systems.

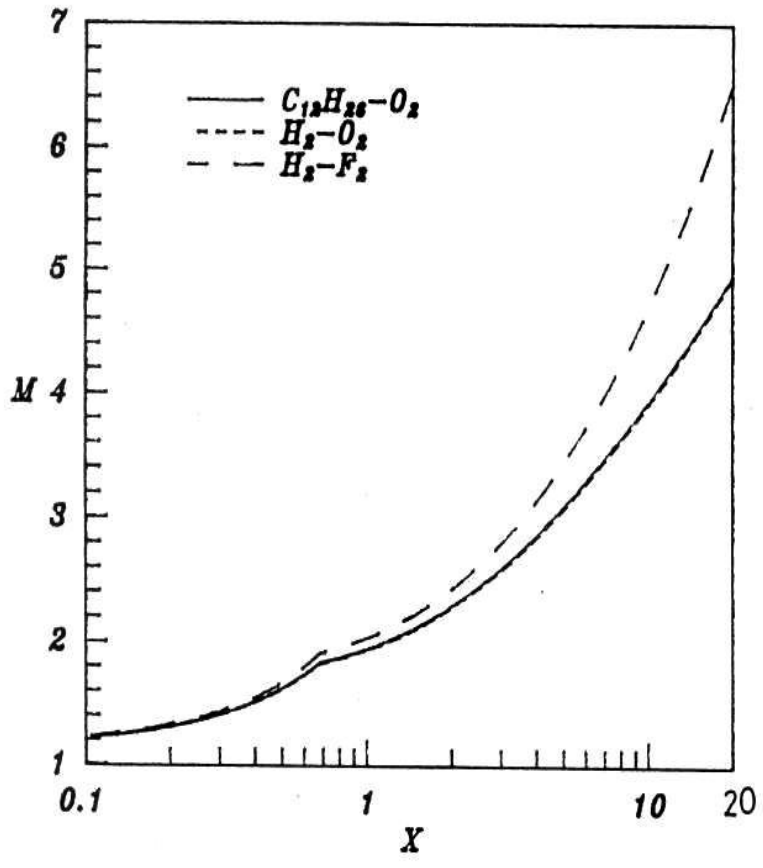

(i) Wall

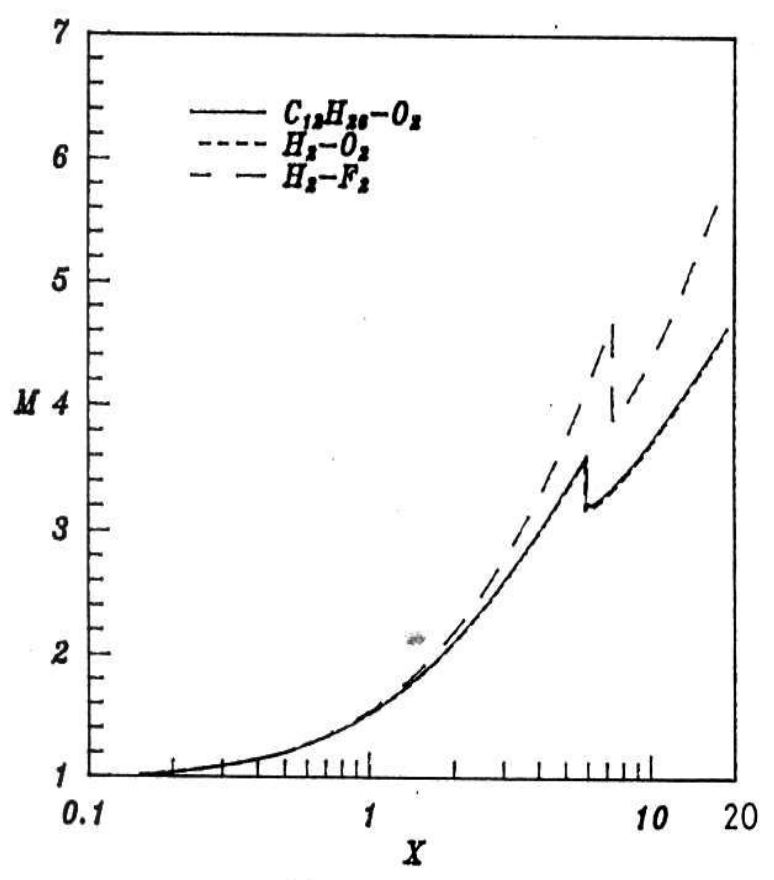

(ii) Centerline

Figure (11). Comparison of the flow Mach number as predicted by the three fuel-oxidizer systems. 


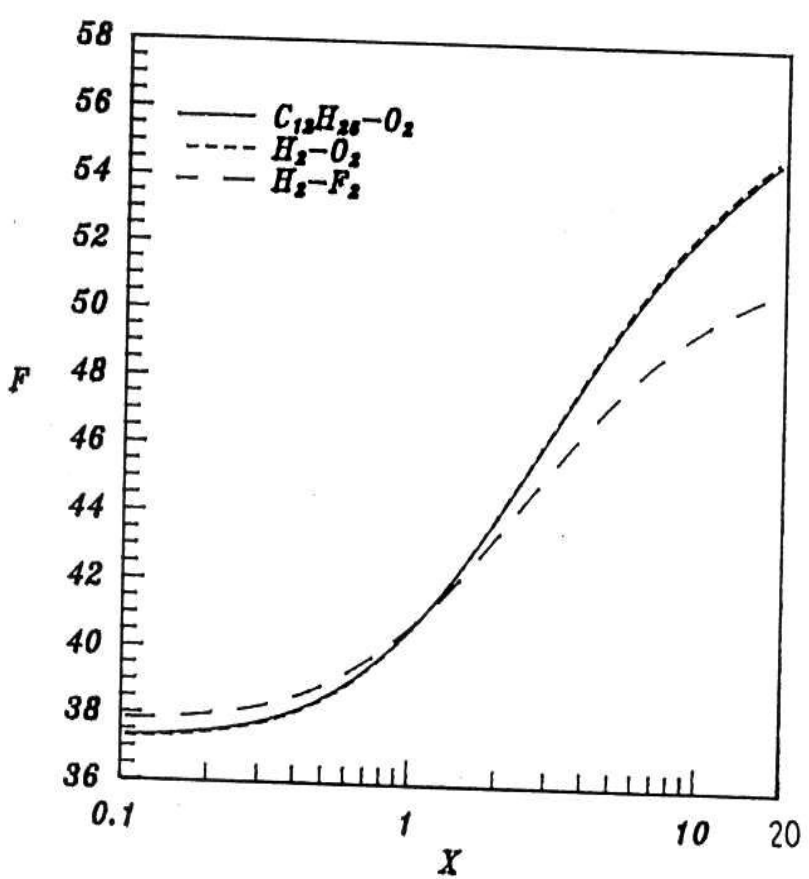

(a) Thrust

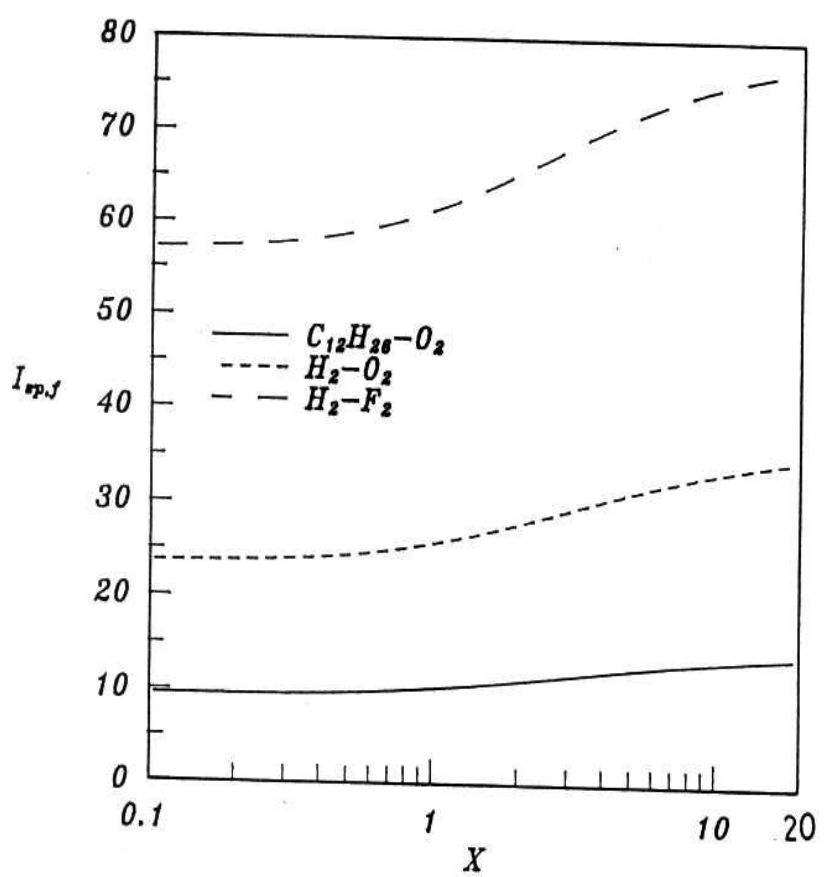

(c) Specific impulse based on fuel consumption

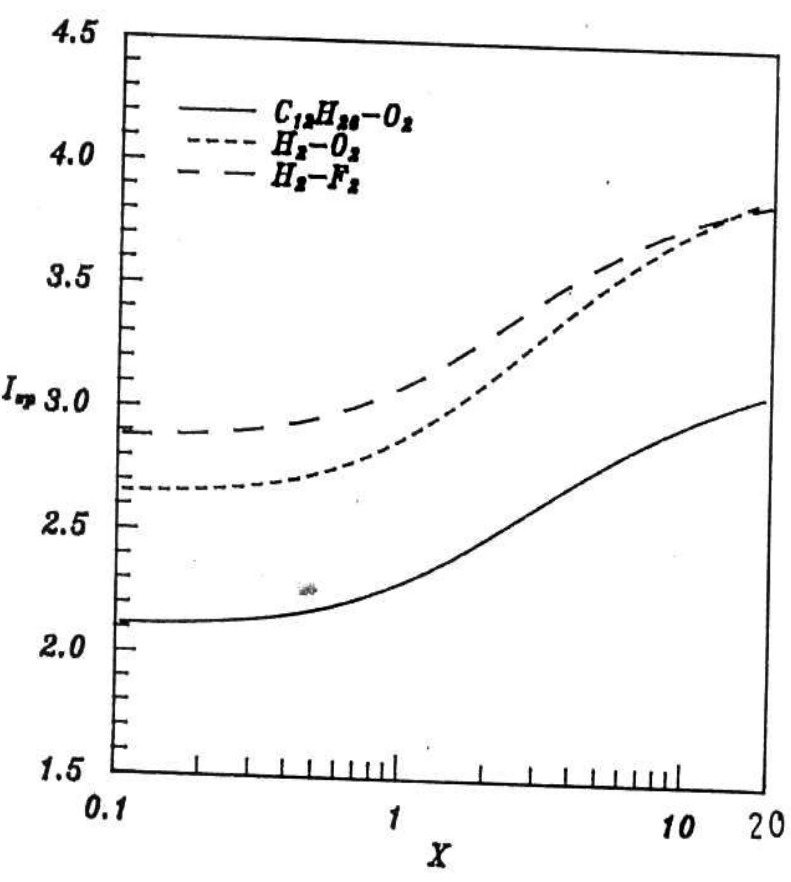

(b) Specific impulse

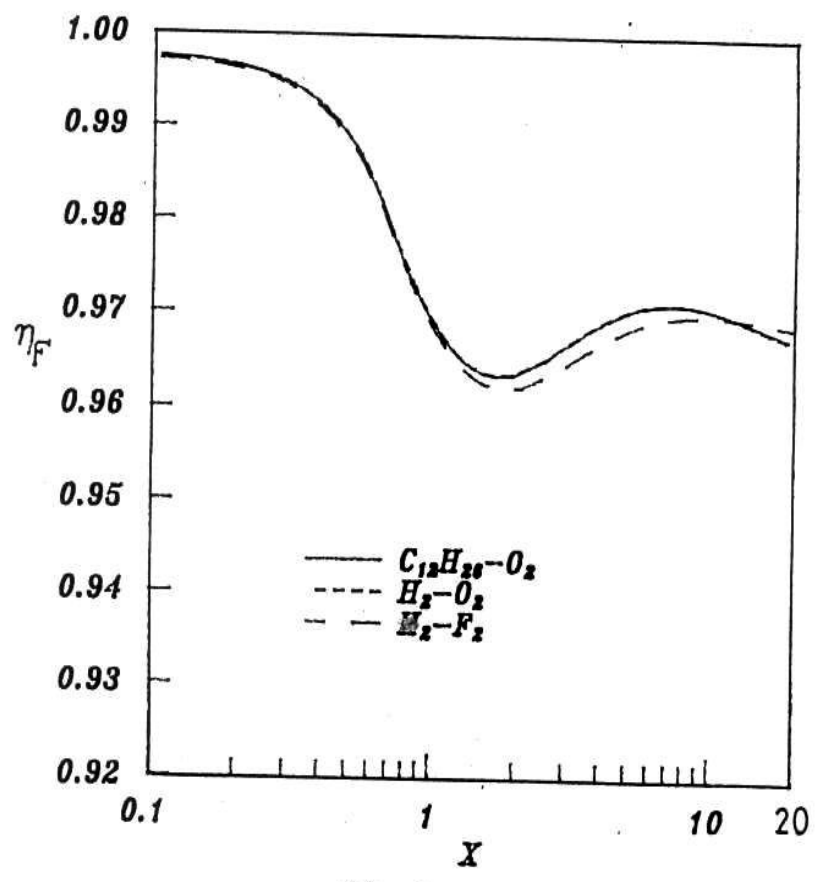

(d) Thrust efficiency

Figure (12). Comparison of the propulsion parameters for the three fuel-oxidizer systems. 